\title{
Three Patients with Full Facial Transplantation
}

\section{Citation}

Pomahac, Bohdan, Julian Pribaz, Elof Eriksson, Ericka M. Bueno, J. Rodrigo Diaz-Siso, Frank J. Rybicki, Donald J. Annino, et al. 2012. "Three Patients with Full Facial Transplantation." N Engl J Med 366 (8) (February 23): 715-722. doi:10.1056/nejmoa1111432.

\section{Published Version}

doi:10.1056/NEJMoa1111432

\section{Permanent link}

http://nrs.harvard.edu/urn-3:HUL.InstRepos:32659617

\section{Terms of Use}

This article was downloaded from Harvard University's DASH repository, and is made available under the terms and conditions applicable to Other Posted Material, as set forth at http:// nrs.harvard.edu/urn-3:HUL.InstRepos:dash.current.terms-of-use\#LAA

\section{Share Your Story}

The Harvard community has made this article openly available.

Please share how this access benefits you. Submit a story.

Accessibility 


\section{BRIEF REPORT}

\section{Three Patients with Full Facial Transplantation}

\author{
Bohdan Pomahac, M.D., Julian Pribaz, M.D., Elof Eriksson, M.D., \\ Ericka M. Bueno, Ph.D., J. Rodrigo Diaz-Siso, M.D., Frank J. Rybicki, M.D., \\ Donald J. Annino, M.D., Dennis Orgill, M.D., Edward J. Caterson, M.D., \\ Stephanie A. Caterson, M.D., Matthew J. Carty, M.D., Yoon S. Chun, M.D., \\ Christian E. Sampson, M.D., Jeffrey E. Janis, M.D., Daniel S. Alam, M.D., \\ Arturo Saavedra, M.D., Joseph A. Molnar, M.D., Thomas Edrich, M.D., \\ Francisco M. Marty, M.D., and Stefan G. Tullius, M.D.
}

\section{SUMMARY}

Unlike conventional reconstruction, facial transplantation seeks to correct severe deformities in a single operation. We report on three patients who received full-face transplants at our institution in 2011 in operations that aimed for functional restoration by coaptation of all main available motor and sensory nerves. We enumerate the technical challenges and postoperative complications and their management, including single episodes of acute rejection in two patients. At 6 months of followup, all facial allografts were surviving, facial appearance and function were improved, and glucocorticoids were successfully withdrawn in all patients.

$\mathrm{P}$ ACIAL TRANSPLANTATION IS A SINGLE, COMPLEX OPERATION INTENDED to transform severely deformed features to near-normal appearance and function with the use of techniques that conventional plastic surgery cannot match. ${ }^{1}$ Since 2005, a total of 18 patients have received transplants with promising results. ${ }^{2-7}$ Most facial transplantations have been designed to restore partial-face defects; fullface transplantations include the forehead, eyelids, nose, lips, chin, and cheeks ${ }^{8,9}$ with or without underlying bone. Full-face transplantation has been considered nearly impossible because of the complexity of the blood supply as well as ethical, psychological, and social implications. We report our initial experience in full-face transplantation in three patients.

\section{METHODS}

\section{PATIENTS}

All patients provided written informed consent to participate in the clinical trial (ClinicalTrials.gov number, NCT01281267) for face transplantation, as approved by the human research committee at Brigham and Women's Hospital and by the Army Medical Research and Materiel Command Human Research Protection Office.

All patients were evaluated by our multidisciplinary team before participation. ${ }^{10,11}$ Their medical histories are summarized in Table 1. Pretransplantation frontal photographs are shown in Figure 1, and pretransplantation profile photo-
From the Department of Surgery, Division of Plastic Surgery (B.P., J.P., E.E., E.M.B., J.R.D.-S., D.O., E.J.C., S.A.C., M.J.C., Y.S.C., C.E.S.), Applied Imaging Science Laboratory, Department of Radiology (F.J.R.), Department of Surgery, Division of Otolaryngology (D.J.A.), Department of Dermatology (A.S.), Department of Anesthesiology, Perioperative and Pain Medicine (T.E.), Department of Medicine, Division of Infectious Disease (F.M.M.), and Department of Surgery, Division of Transplant Surgery (S.G.T.), Brigham and Women's Hospital, Boston; the Department of Plastic Surgery, University of Texas Southwestern Medical Center, Dallas (J.E.J.); the Section of Facial Plastic and Reconstructive Surgery, Head and Neck Institute, Cleveland Clinic, Cleveland (D.S.A.); and the Department of Plastic and Reconstructive Surgery, Wake Forest University School of Medicine, Winston-Salem, NC (J.A.M.). Address reprint requests to Dr. Pomahac at the Department of Surgery, Division of Plastic Surgery, Brigham and Women's Hospital, 75 Francis St., Boston, MA 02115, or atbpomahac@partners.org.

This article (10.1056/NEJMoal111432) was published on December 28, 2011, at NEJM .org.

N Engl J Med 2012;366:715-22.

Copyright @) 2011 Massachusetts Medical Society. 
graphs are shown in Figure 1 in the Supplementary Appendix, available with the full text of this article at NEJM.org.

After extensive discussion of the indications, risks, and benefits, which included input from an ethicist, treatment by full-face transplantation was elected by all three patients in an attempt to enhance function and appearance. The New England Organ Bank identified and obtained consent for organ donation from families of suitable brain-dead donors who were matched with the patients according to sex and skin color. In addition, donors and recipients were matched on the basis of several clinical characteristics (Table 1), including negative T- and B-cell crossmatching. Our surgeons were divided into teams with specific objectives during the operations.

\section{TRANSPLANTATION PROCEDURES}

In each instance, one team performed facial allograft recovery that isolated all major motor and sensory nerves and arterial and venous components (Table 1 in the Supplementary Appendix). Another team recovered radial forearm flaps to act as sentinel tissue from Donors 1 and 2. Another two teams recovered the upper limbs from Donor 3. All recovered allografts were perfused with University of Wisconsin solution and transported in an ice-water slurry.

In synchronization with the donor operation, another team removed the skin, contoured the facial tissue remnants, and isolated bilateral motor- and sensory-nerve branches and neck vessels of the recipient. The residual functioning portions of the recipients' faces were preserved to allow them to return to their pretransplantation level of function in the event of transplant failure. ${ }^{11}$ All facial-nerve branches and sensory nerves were anastomosed unless they were not present because of injury (Table 1 in the Supplementary Appendix). Donor skin was tailored to the recipients' defects for optimal contour. All facial allografts had complete perfusion after implantation.

A third team transplanted the sentinel skin flaps to an inconspicuous area (in Patient 1 ) and to a hand contracture (in Patient 2); Patient 3 underwent simultaneous bilateral transplantation of the upper limbs, a procedure that is not described in detail in this report. The patients were initially treated in the intensive care unit and were subsequently transferred to the surgical ward until discharge (Table 2).

\section{IMMUNOSUPPRESSION}

All patients received mycophenolate mofetil, methylprednisolone, and rabbit antithymocyte globulin before allograft reperfusion. Maintenance immunosuppression consisted of mycophenolate mofetil, tacrolimus, and prednisone taper (Table 2, and Fig. 2 in the Supplementary Appendix). We obtained skin-biopsy samples from facial and sentinel allografts periodically and during suspected rejection (Table 2). Biopsy samples were graded according to the Banff 2007 scale. $^{12}$ Immunosuppression was adjusted on the basis of clinical judgment, biopsy results, and tacrolimus trough levels (Table 2). Perioperative antibacterial prophylaxis consisted of vancomycin and cefazolin and was modified according to perioperative findings; Patients 2 and 3 also received perioperative antifungal prophylaxis with micafungin. All patients received trimethoprim-sulfamethoxazole and valganciclovir prophylaxis against Pneumocystis jirovecii and cytomegalovirus, respectively, for at least 6 months.

Postoperatively, all patients had tracheotomies placed; these were removed within 3 months in all cases. All patients had access to continuous counseling from psychiatrists and social workers.

\section{RESULTS}

\section{PATIENT 1}

Patient 1 received 24 units of packed erythrocytes and 17 units of blood obtained by intraoperative cell salvage (Cell Saver, Haemonetics) during the operation, a volume of blood that was greater than anticipated. On day 3, the patient reported that his olfaction was restored. On day 8 , secretion from a suture line grew Candida albicans and Pseudomonas aeruginosa. Treatment with micafungin and cefepime was initiated. On day 13, drainage of a recurrent submental collection was identified as sterile saliva. Botulinum toxin was injected into each of the donor's submandibular glands to decrease saliva production, and fluconazole and amoxicillin-clavulanic acid were prescribed for further antimicrobial treatment. The submental lymph nodes of the allograft became markedly enlarged (Fig. 3 in the Supplementary Appendix), and reactive changes were noted in biopsy sam- 


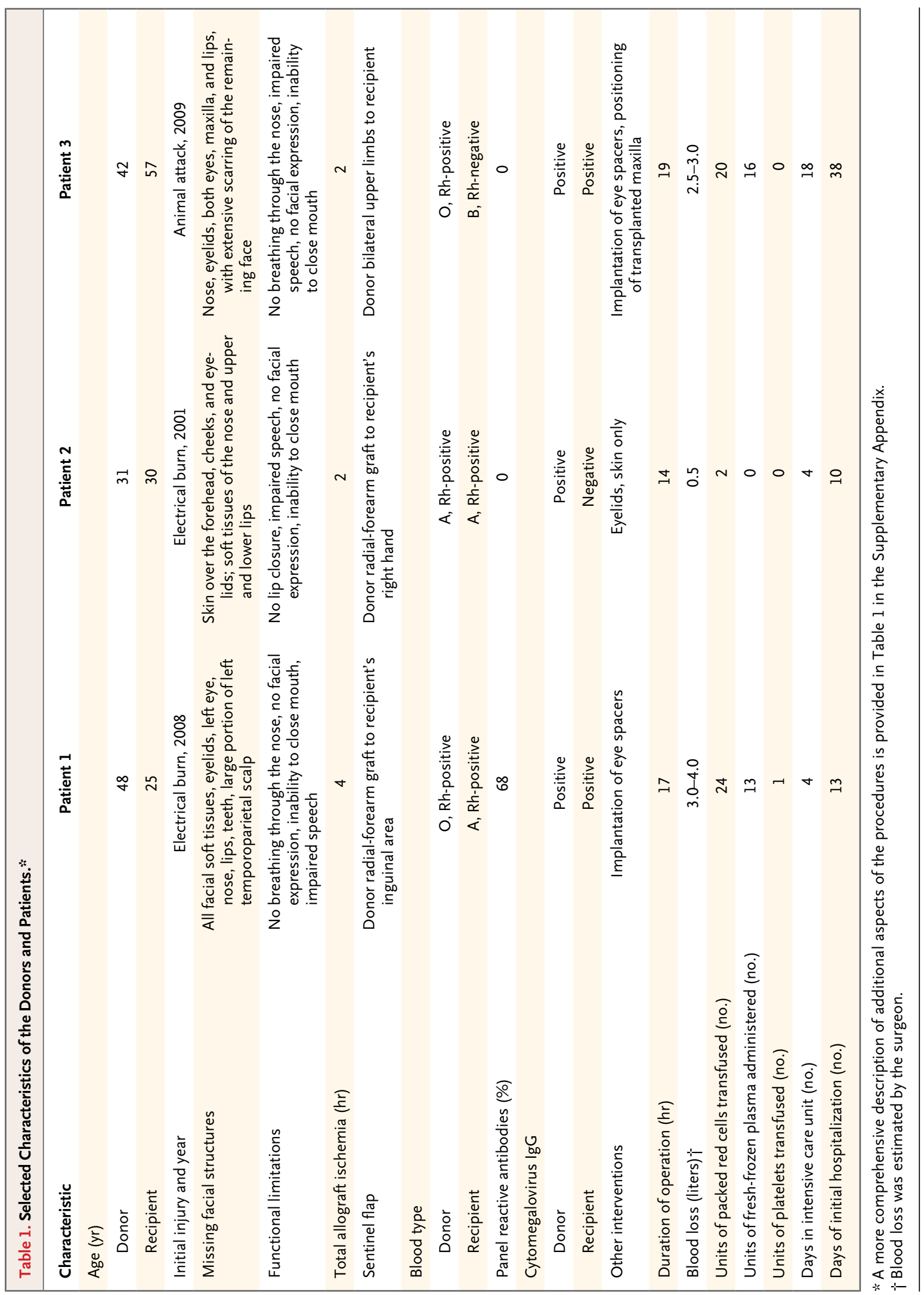

N ENGLJ MED 366;8 NEJM.ORG FEBRUARY 23, 2012 


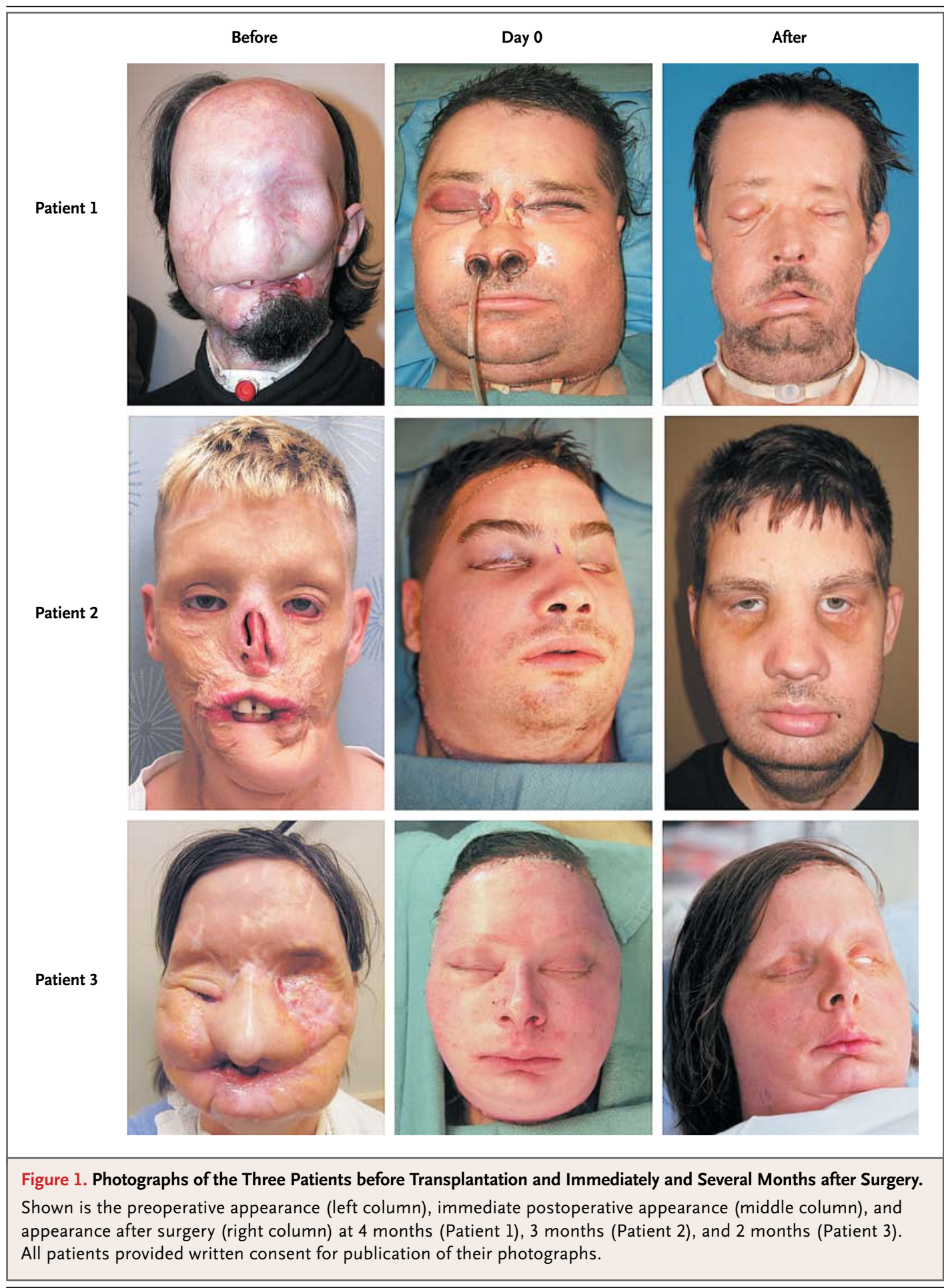

ples, although skin-biopsy samples did not sug- of right-sided muscle groups and restoration of

Videos are available at NEJM.org gest rejection. On day 116, redundant neck skin was partially resected (Table 2).

At 4 months, sensation had returned on the right side of the transplant, along with movement facial aesthetics (Fig. 1, and Fig. 9 in the Supplementary Appendix; and video 1, available at NEJM .org). Sensation had not returned on the left side, where sensory nerves were not connected. 


\section{PATIENT 2}

Patient 2 received 2 units of packed erythrocytes. On day 4, he was able to talk, eat, and drink. On day 20, erythema and increased swelling of the facial allograft and sentinel flap (Fig. 4 in the Supplementary Appendix) prompted a diagnosis of acute rejection, which was confirmed on face and sentinel-graft biopsies (grade 2 rejection) (Fig. 5 in the Supplementary Appendix). The episode was successfully treated with pulse doses of methylprednisolone. For the first 3 months, the patient recovered well, aside from several episodes of unexplained fever. At 4 months, he was admitted for treatment of polymicrobial bacteremia, attributed to either his long-term peripherally inserted central catheter or periodontal infection. He was treated with vancomycin, levofloxacin, and the extraction of two teeth (Table 2).

At 3 months, Patient 2 had a return of sensation in the forehead and chin and a return of gross lip motion, along with restoration of facial aesthetics (Fig. 1, and Fig. 10 in the Supplementary Appendix; and video 2, available at NEJM.org).

\section{PATIENT 3}

Patient 3 received 20 units of packed erythrocytes. This blood loss was expected because of the extent of the combined operation. On day 2, aspiration pneumonia complicated by septic shock developed, which caused irreversible ischemic changes and gradual thrombosis of both transplanted upper limbs. Despite salvage attempts with dobutamine, anticoagulation, and brachial plexus blocks, the upper-limb allografts were removed on day 5 , preserving the patient's own right thumb. On day 30, the patient underwent maxillofacial computed tomography to assess lymphadenopathy. Craniofacial three-dimensional reconstruction was performed to assess maxillomandibular occlusion (Fig. 6 in the Supplementary Appendix). On day 54, erythema and swelling prompted a diagnosis of acute rejection (Fig. 7 in the Supplementary Appendix), which was confirmed on biopsy (grade 2 rejection) (Fig. 8 in the Supplementary Appendix). The episode was successfully treated with pulsed methylprednisolone at a dose of $500 \mathrm{mg}$ per day for 3 days. At 2 months, the patient was able to breathe through her nose and mouth (Table 2).

At 3 months, there was a return of sensation in the transplant, along with restoration of facial aesthetics (Fig. 1, and Fig. 11 in the Supplemen- tary Appendix). There was no return of motor function at this time.

\section{DISCUSSION}

Full-face transplantation presents unique surgical, immunologic, and ethical challenges. Our operative strategy uses all major motor and sensory nerves to provide gradual proprioceptive feedback as the graft recovers, facilitating cortical integration of the new face. Our efforts to perform motor neurorrhaphies as close as possible to the effector muscle appeared to result in targeted reinnervation.

It was thought that facial vessels alone could not perfuse the entire face and anterior scalp and that superficial temporal vessels must be included in full-face allografts, ${ }^{13-15}$ complicating and prolonging allograft recovery in a major way. In addition, it was recommended to recover parotid glands to avoid facial-nerve injury, at the expense of excessive bulk at the sides of the face, ${ }^{7}$ unless superficial parotidectomy was performed in the recipient. ${ }^{16}$ We carried out fullface allograft recovery by a planned, simplified vascular supply guided by precise vascular mapping in the recipient. ${ }^{17,18}$ Facial recovery was performed in under 4 hours in all three cases. Although superficial temporal vessels may be needed to sustain allograft ears, we speculate that many patients would benefit from the approach we describe.

All patients had postoperative infections of differing severity, and they all recovered. Single episodes of rejection in Patients 2 and 3 were successfully managed.

One of the unique features of full-face transplantation is the large area of direct contact between allograft and recipient tissues. This may result in substantial growth of new vessels, which should lead to secondary revascularization. Such direct angiogenesis may constitute an alternative source of allograft blood supply and would require further investigation to confirm.

The sentinel flap was planned as an alternative site by which to monitor rejection. Sentinel flaps were preferably positioned in sites needing functional improvement. In two of our four facetransplant recipients (the first one was described previously ${ }^{5}$ ), the sentinel flap indicated rejection more accurately than the facial allograft because it was less prone to confounding facial-skin con- 


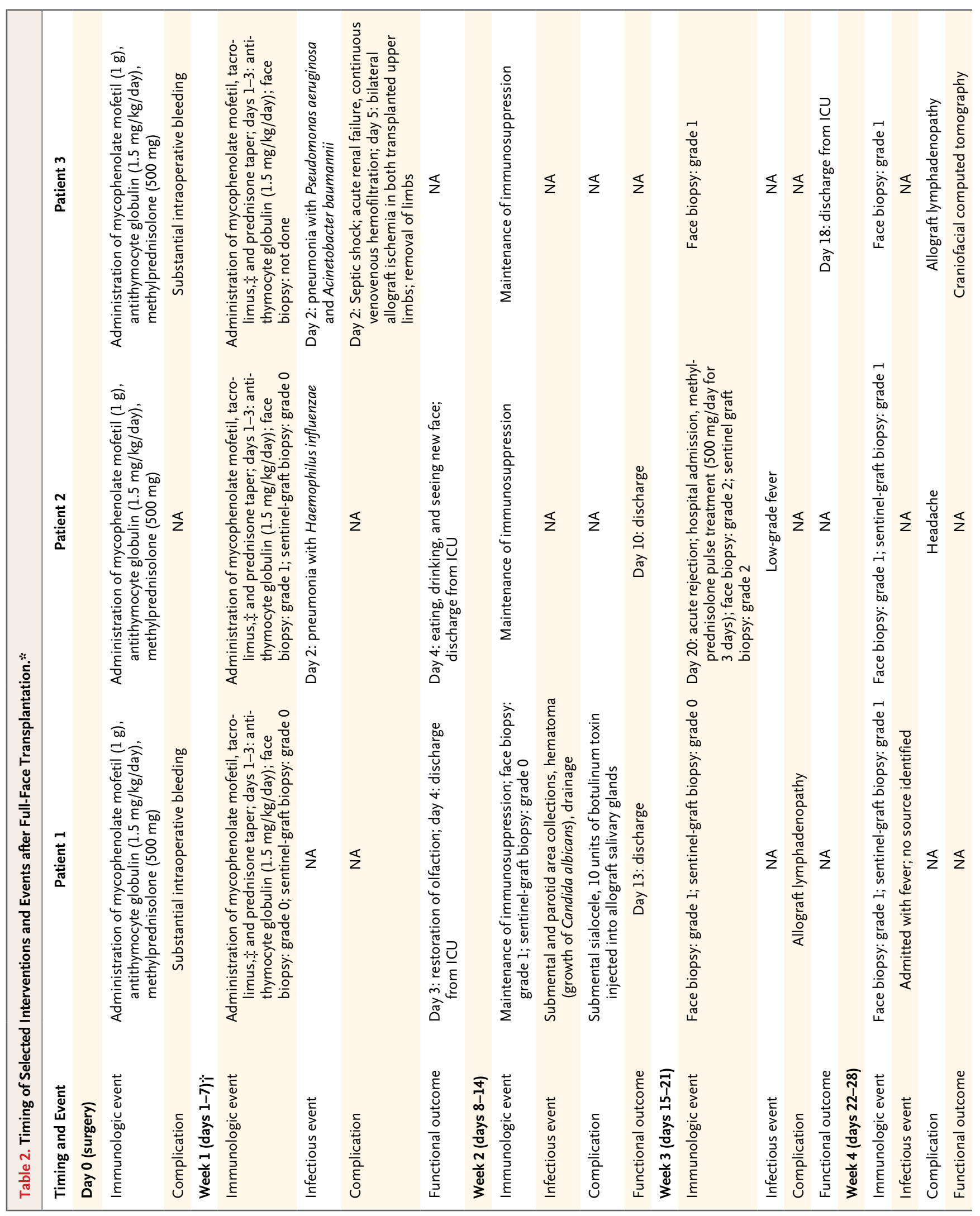



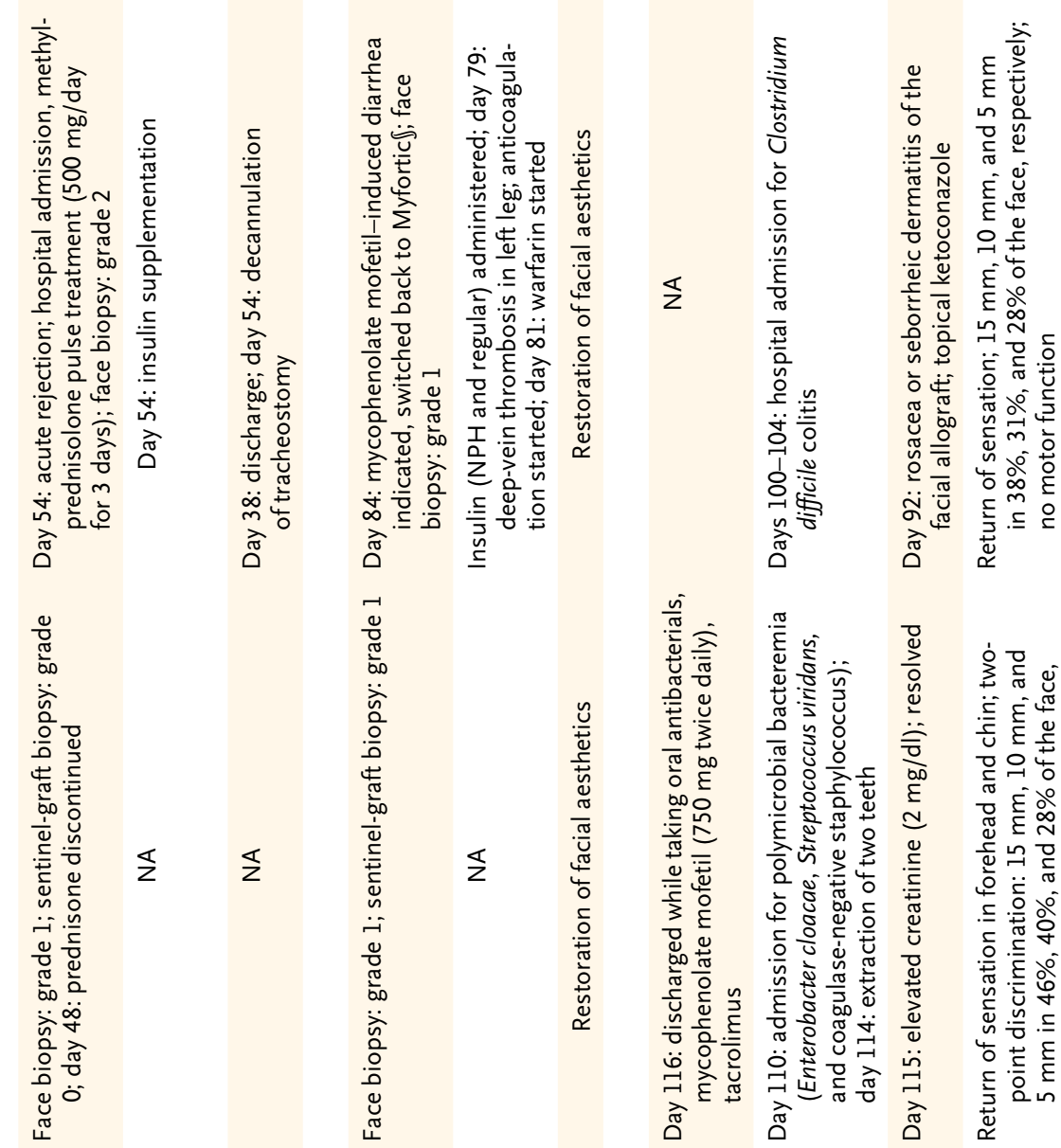

$$
\text { (n) }
$$

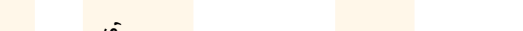

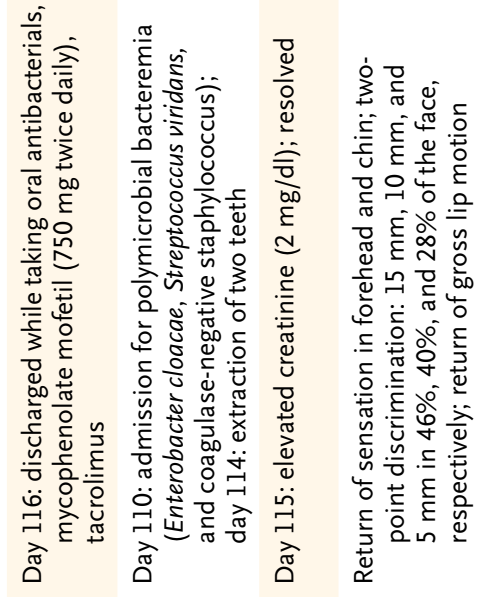
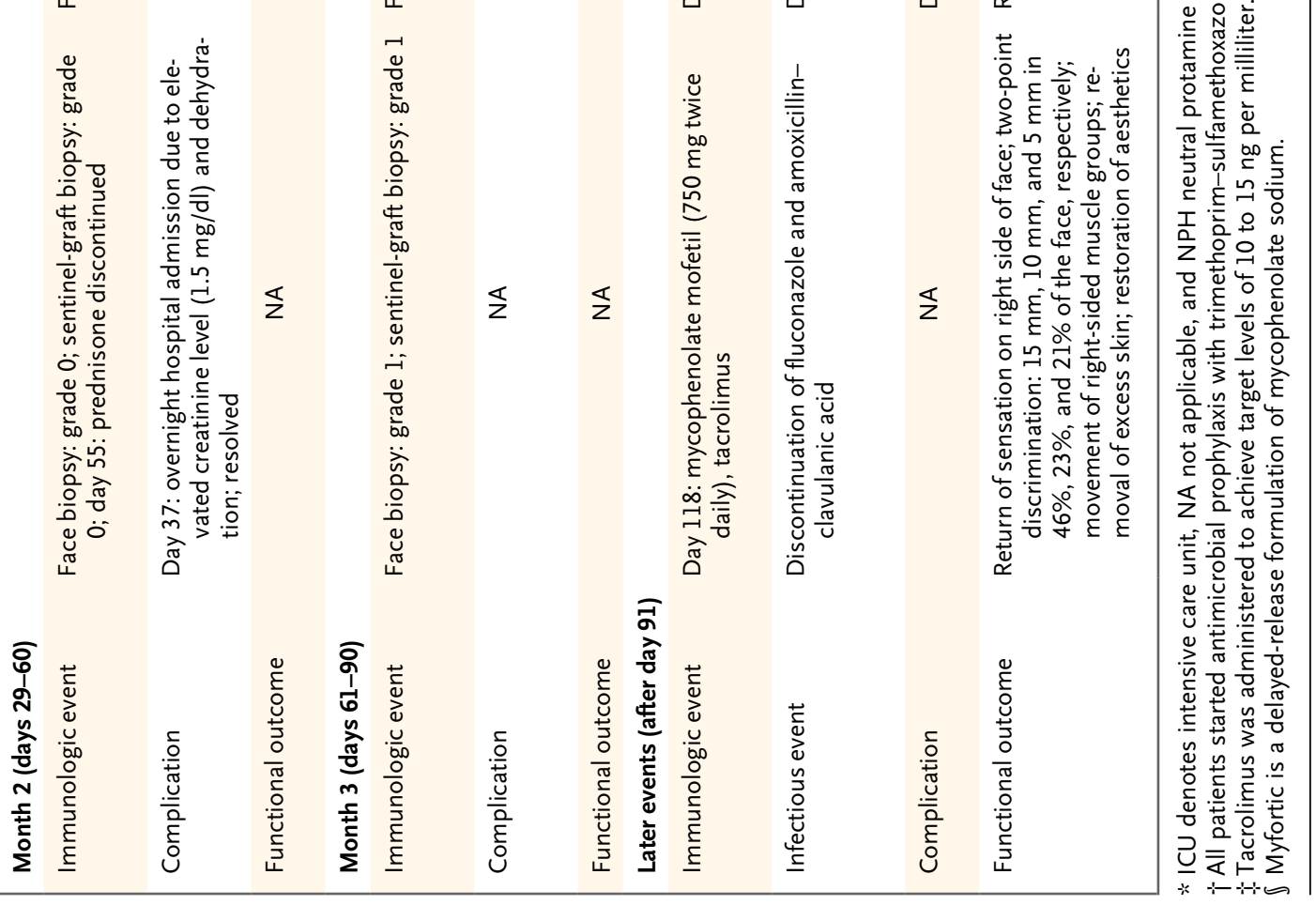

N ENGLJ MED 366;8 NEJM.ORG FEBRUARY 23, 2012

The New England Journal of Medicine 
ditions, since a facial allograft may show erythema and local inflammation from environmental exposure or from conditions such as rosacea or dermatitis. ${ }^{19}$

We expected major immediate and gradual changes in facial appearance in these patients. We anticipated that the underlying skeleton and facial volume would shape the final facial appearance, making resemblance to the donors unlikely. It is our subjective opinion, as well as that of two of the donor families, that the patients do not look like their donors (the remaining donor family has chosen to remain unknown).

In conclusion, on the basis of our experience with three patients who had severe facial deformities resulting from various injuries, we have shown that it is feasible to perform face transplantation with the use of a consistent, complex protocol. Despite important adverse events and a short follow-up, this study provides further sup- port for the concept that full-face transplantation is able to restore functional defects and to resurface major deficits with the use of conventional immunosuppression and early glucocorticoid withdrawal. We will continue to assess functional reintegration, as measured by standardized restoration of motor and sensory function, over time.

\footnotetext{
Supported by a research contract (W911QY-09-C-0216) between the Department of Defense and Brigham and Women's Hospital under the Biomedical Translational Initiative.

Disclosure forms provided by the authors are available with the full text of this article at NEJM.org.

We thank Benoit Lengele for hosting cadaver dissections at the Catholic University of Louvain; all members of the multidisciplinary face-transplantation team and the administration at Brigham and Women's Hospital; the Partners Human Research Committee for enabling the interventions described here; Lisa Quinn for her outstanding work as a study coordinator; and the donor families and the New England Organ Bank (in particular, Christopher Curran) for their enthusiasm, dedication, and success in the safe procurement of the facial allografts.
}

\section{REFERENCES}

1. Pomahac B, Nowinski D, Diaz-Siso JR, et al. Face transplantation. Curr Probl Surg 2011;48:293-357.

2. Dubernard JM, Lengelé B, Morelon E, et al. Outcomes 18 months after the first human partial face transplantation. $\mathrm{N}$ Engl J Med 2007;357:2451-60.

3. Guo S, Han Y, Zhang X, et al. Human facial allotransplantation: a 2-year follow-up study. Lancet 2008;372:631-8.

4. Lantieri L, Hivelin M, Audard V, et al. Feasibility, reproducibility, risks and benefits of face transplantation: a prospective study of outcomes. Am J Transplant 2011; 11:367-78.

5. Pomahac B, Pribaz J, Eriksson E, et al. Restoration of facial form and function after severe disfigurement from burn injury by a composite facial allograft. Am J Transplant 2011;11:386-93.

6. Lantieri L, Meningaud JP, Grimbert P, et al. Repair of the lower and middle parts of the face by composite tissue allotransplantation in a patient with massive plexiform neurofibroma: a 1-year follow-up study. Lancet 2008;372:639-45.

7. Alam DS, Papay F, Djohan R, et al. The technical and anatomical aspects of the world's first near-total human face and maxilla transplant. Arch Facial Plast Surg 2009;11:369-77.
8. Lengelé BG. Current concepts and future challenges in facial transplantation. Clin Plast Surg 2009;36:507-21.

9. Barret JP, Gavaldà J, Bueno J, et al. Full face transplant: the first case report. Ann Surg 2011;254:252-6.

10. Bueno EM, Diaz-Siso JR, Pomahac B. A multidisciplinary protocol for face transplantation at Brigham and Women's Hospital. J Plast Reconstr Aesthet Surg 2011;64:1572-9.

11. Pomahac B, Diaz-Siso JR, Bueno EM Evolution of indications for facial transplantation. J Plast Reconstr Aesthet Surg 2011;64:1410-6.

12. Cendales LC, Kanitakis J, Schneeberger S, et al. The Banff 2007 working classification of skin-containing composite tissue allograft pathology. Am J Transplant 2008;8:1396-400.

13. Meningaud JP, Benjoar MD, Hivelin M, Hermeziu O, Toure G, Lantieri L. The procurement of total human face graft for allotransplantation: a preclinical study and the first clinical case. Plast Reconstr Surg 2010 June 15 (Epub ahead of print).

14. Meningaud JP, Paraskevas $A$, Ingallina $F$, Bouhana E, Lantieri L. Face transplant graft procurement: a preclinical and clinical study. Plast Reconstr Surg 2008;122: 1383-9.
15. Wang HY, Li QF, Zheng SW, et al. Cadaveric comparison of two facial flap-harvesting techniques for alloplastic facial transplantation. J Plast Reconstr Aesthet Surg 2007;60:1175-81.

16. Meningaud JP, Hivelin M, Benjoar MD, Toure G, Hermeziu O, Lantieri L. The procurement of allotransplants for ballistic trauma: a preclinical study and a report of two clinical cases. Plast Reconstr Surg 2011;127:1892-900.

17. Soga S, Ersoy H, Mitsouras D, et al. Surgical planning for composite tissue allotransplantation of the face using 320-detector row computed tomography. J Comput Assist Tomogr 2010;34:766-9. 18. Soga S, Pomahac B, Mitsouras D, et al. Preoperative vascular mapping for facial allotransplantation: four-dimensional computer tomographic angiography versus magnetic resonance angiography. Plast Reconstr Surg 2011;128:883-91.

19. Saavedra AP, Bueno EM, Granter SR, Pomahac B. Transmission of donor-specific skin condition from donor to recipient of facial allograft. Am J Transplant 2011;11: 1340.

Copyright (C) 2011 Massachusetts Medical Society. 